\title{
Evaluating the quality of work-integrated learning curricula: a comprehensive framework
}

\author{
Calvin Smith \\ Griffith University, Brisbane, Australia
}

\begin{abstract}
There are many different forms that work-integrated learning (WIL) takes, and variants go by a range of different names. Based on current literature key dimensions, shared by the various and disparate forms of WIL curricula, were identified and operationalised in a measurement model. The key dimensions identified were: authenticity; integrated learning supports (both at university and the workplace); alignment (of teaching and learning activities and assessments with integrative learning outcomes); supervisor access; and induction / preparation processes. It is suggested that variations in the way that WIL courses or subjects are designed within these dimensions are the basis for different expressions of the quality of such courses. A latent construct measurement model was developed and validated with a sample of Australian and UK students. This paper presents the model and discusses the results of the validation study. It is proposed that the measures validated in this study will be useful for evaluating a wide variety of WIL curricula.
\end{abstract}

\section{Introduction}

Work integrated learning (WIL) is a curriculum design in which students spend time in professional, work, or other practice settings relevant to their degrees of study, and to their occupational futures. Students in WIL courses are encouraged by the specifically designed activities they engage in (e.g. reflective journaling; the creation of a commercial product; the conduct of research; or other discipline- or professionappropriate means) to apply and learn disciplinary knowledge and skills in a realworld context. WIL curricula can include such familiar notions as placements, internships, practica, supervised practice, and even simulations. Importantly WIL is not the same as work experience or work-based learning, neither of which require students to specifically learn, apply or integrate canonical disciplinary knowledge.

WIL is becoming increasingly important, and is a topic for public and professional debates both within and about higher education. Government policies that focus on productivity gains (Yorke, 2006:3), employer demands (Harvey, 2005) and students' exigent search for programs that will provide quick returns on their investment, are causing higher education institutions to more deeply and more seriously engage with the WIL agenda. WIL may be seen by some as a strategic way for institutions to respond to the demands of the 'enterprise' culture that places pressure on higher education institutions to produce graduates who are "work-ready" (Ballantine \& McCourt Larres, 2007; Precision Consultancy \& Commonwealth of Australia, 2007).

Many benefits are said to accrue to universities, to students, and to the community and industry partners who become involved in WIL curricula. For institutions, benefits include having a market advantage to attract students, obtaining national and international grants for collaborative research projects, and attracting sponsorship (so called third stream funding) from different industries (Abeysekera, 2006; Eames, 
2003; Wright, 1990). WIL engagement also helps to fulfil university missions, such as:

- providing education that responds to present and future needs (Alderman \& Milne, 2005);

- providing learning that would be of use to the society and not merely adding to students' disciplinary knowledge base (Barnett, Parry, \& Coate, 2001);

- engaging more actively in the community through its partnership with the different industries and community organisations (Alderman \& Milne, 2005; Eames, 2003; Keating, 2006); and

- producing more employable and work-ready graduates (Crebert, Bates, Bell, Patrick, \& Cragnolini, 2004; Orrell, 2004; Precision Consultancy \& Commonwealth of Australia, 2007; Universities Australia, 2008).

So popular is the idea of WIL that Universities Australia, the National consortium of Australian universities, published a position paper advocating a national internship scheme in order to address both a national skills shortage, and student employability, in a systematic fashion (Universities Australia, 2008).

"Work-integrated learning" is relatively new jargon that focuses attention on the integration of discipline learning and workplace practice or application; the term puts at the heart of the curriculum its purposes, in a way that other terms for ostensibly the same thing (e.g. placement, internship) do not. Moreover, it embodies a clear distinction between WIL and some theories of work(place)-based learning which do not focus on the goal of integrating disciplinary or canonical knowledge, skills, professional practice or identity with the fact of being in a workplace, doing work (see Billett, 2001; Boud \& Solomon, 2001).

Thus, although the concept of students being placed in the workplace to get work experience is not new, the rationale behind WIL goes beyond merely providing the physical environment of a workplace as a site for students to experience work or to learn professional practice. As more tertiary institutions engage with the WIL agenda, more research is being done on the basic and peripheral issues around providing the best learning through work integrated learning curricula (Duignan, 2003; Orrell, 2004; Thacker, 2002; University of Western Australia, 1999). Much of this work focuses on issues related either to learning and teaching or to administration and management. Furthermore, the literature is replete with detailed descriptions of specific strategies and curriculum implementations. What appears to be missing is a unifying evaluation framework that captures the essential, pedagogically relevant features that are shared by most or all WIL-type curricula.

Evaluating higher education curricula using quantitative measurement models is not new. For instance in Australia there exists the Course Experience Questionnaire (CEQ) (Ramsden, 1991), the extended CEQ (McInnes \& James, 2003; McInnis, Griffin, James, \& Coates, 2001), the University of Queensland Student Experience Survey (UQSES) (Bath, Smith, Stein, \& Swann, 2004; Smith \& Bath, 2006) and others (e.g. Kember et al., 2000). These tools however, were all designed to evaluate the more typical higher education experience - that of the taught class - rather than WIL courses.

One attempt to devise an evaluation instrument for WIL is that reported by Martin (1997) who used the conceptual structures of the CEQ and applied these to workexperience curricula (Work Experience Questionnaire or WEQ). One additional scale, 
the Menial Tasks Scale, attempted to capture some of the pedagogically important detail of work-based curriculum experiences. This scale has been later utilised by Freestone (2007) to assess the views of urban planning students regarding their placement. While the measures in the WEQ maintained reliability and construct validity in these studies, the overall approach is somewhat flawed. The WEQ does not measure the essential pedagogically-relevant characteristics of WIL curricula, especially the authenticity of the workplace experience and the incorporation of integrative learning as a learning outcome, the importance of which are highlighted later in this paper.

Concerns over the paucity of effective approaches to evaluation are further confirmed by $\mathrm{Hu}$ and colleagues (X. Hu, Abadeer, \& Husman, 2009). Despite the development of WIL programs, which are now a common feature of most engineering degrees within Australian universities, Hu and colleagues reveal that, since much of the past evaluative research for WIL programs has focused upon certain styles of WIL (i.e., cooperative education), there is a shortage of research regarding engineering-based work-experience programs, and that evaluating such programs is not "standard practice", nor is there "a well accepted method for their evaluation" (X. Hu et al., 2009:918). Prior evaluation investigations have used a variety of methodologies from quantitative measures (as outlined previously) and regression analysis, to qualitative methods which have included simple anecdotal evidence (Radcliffe \& Brown, 2003), focus groups (Crebert et al., 2004), and attitudinal surveys (Eakins, 2000).

Though there is a general consensus of the "wider good" of WIL courses, with Martin (Martin, 1997) highlighting that many studies have shown work-based education is effective in producing graduates with increased capabilities, important gaps remain. Beyond mere gaps in our approaches to evaluation, however, as (X. Hu et al., 2009) importantly note, major research gaps remain in understanding how such programs facilitate these outcomes. As such, these authors assert:

...simply evaluating generic skills outcome alone is not sufficient. Stakeholders need to also understand which aspects of the work experience program contribute to the effectiveness of the program in developing students' generic skills (X. Hu et al., 2009:922).

While qualitative methods are useful in generating rich insight, quantitative methods have the potential to shed further light on what aspects of a WIL program contribute to particular student outcomes. Given the outlined research gaps, methodological issues and the wide variety of WIL type programs, an evaluative framework that transcends the specific, practical minutiae distinguishing one implementation from another, must be developed. Such a framework could then be applied across a wide range of specific instances, and would be of particular import for WIL programs with a smaller body of relevant research. Such a framework should allow for evaluation of both major WIL curricula components and outcomes to further generate insight into what and how particular outcomes are facilitated. It is in this context that the following framework was developed. This paper concentrates on the first of these issues: the measurement of WIL curricula components through the development of the curriculum framework, its operationalisation and validation of its measures.

The model is first described below; this is followed by an account of the method of development of a WIL curriculum evaluation instrument based on the model; finally details of the empirical validation of the model and instrument are provided. 


\section{A New Evaluation Framework}

This new evaluation framework divides the WIL curriculum structurally and conceptually into six domains or constructs (abbreviations in brackets are used later in identifying scales):

- Authenticity;

- Alignment of teaching and learning activities with integrative learning objectives (Align-TLA);

- Alignment of assessment with integrative learning objectives (Align-Asst);

- Integrated Learning Support (across the two university and workplace sites) (ILS);

- Supervisor Access (Sup. Access); and

- Induction and Preparation Processes (IPP).

In the present study, six independent measurement scales were developed as part of this evaluation framework. The justification for including each specific domain and their corresponding interrelationships are described below.

\section{Authenticity}

Authenticity is at the heart of all workplace-situated learning. Most WIL curricula aim to provide students with a real work environment (physical authenticity) doing real world work. However, authenticity in WIL does not only equate to 'physical authenticity'. It also refers to 'cognitive authenticity' (Herrington \& Herrington, 2006) where students encounter, engage and/or participate in (Moore, 2004) personally meaningful and relevant learning within a particular disciplinary framework (Stein, Andrews, \& Isaacs, 2001). To succeed, WIL curricula need to have the following characteristics:

- They must occur in authentic environments and contexts that will expose the students to real work settings and situations and where they can observe, interact and respond to that particular context (Lave \& Wenger, 1991); and

- Thus, they must feature authentic activities, with complexities that match those in real practice.

The importance of authenticity is highlighted by various authors, where the quality of work placements depends on students having "real world" work experiences and where universities compete to extend the range of such experiences offered to students (Patrick et al., 2008). As Keogh, Sterling and Venables (2007) note, realistic problems require increased engagement and are more motivating. These authors also highlight the importance of having projects that are meaningfully consequential, though not crucial, to the client, so students are motivated to achieve real results for a real client, but are free to learn by making mistakes.

The necessity to evaluate the level of perceived authenticity has also been evidenced in some form within prior instruments such as the WEQ. This instrument incorporated a "menial tasks" scale to measure whether students felt they were only engaging in trivial tasks during their WIL placement (e.g., Freestone et al., 2007; Martin, 1997). Authentic work experiences involve more than just an absence of menial tasks, however, so the current study sought to measure authenticity by assessing whether students felt they were engaging in work that was relevant to the organisation's goals, 
required or allowed to work autonomously, and that the work was important and consequential.

\section{Alignment of both Teaching and Learning Activities (TLAs) and Assessment with integrative learning objectives}

In the evaluation framework alignment is based on Biggs' (1996) notion of the constructive alignment of learning objectives with teaching and learning activities (TLAs) and assessments.

Further, the activities students engage in should be based on the notion of integrative learning, thus developing their ability to integrate the theoretical or disciplinary with practical knowledge and their ability to discern what, when and how such integrated knowledge could be applied. This takes students beyond mere application, the act of making choices consistent with known theory, to developing an understanding as to why those choices are better than ones that are inconsistent with theory. Alignment of both teaching and learning activities (TLAs), and assessment, refers then to alignment with integrative learning.

This idea emphasises the combination, assimilation or connection of theory and practice are the core intellectual activities for students in which "theory becomes part of students' lived experience" (Dymock \& Gerber 2002). It includes not just the connection of theoretical or disciplinary knowledge with their practical or applied counterparts, but also the ability to use such connected knowledge at the right time and the right place; that is the emergence, through integration, of professional 'performativity' (Barnett et al., 2001).

To achieve this, there are some necessary conditions to be met. Learning outcomes and activities should:

- be aimed at developing students' professional identity and abilities;

- emphasize linkages between theory and practice, reflection on the attempt to apply canonical knowledge and skills in the workplace, and reflection on the nature of the work itself, with reference to its fit with state-of-the-art disciplinary thinking (Boud, Keogh, \& Walker, 1985; Boud \& Walker, 1991); and

- allow transfer of learning from university to the workplace (Dymock \& Gerber 2002) and back to university (Duignan, 2003).

To achieve this integrative learning however is no mean feat; it must be deliberately designed into curriculum activities and assessments (Dewey, 1939:19; Radcliffe \& Brown, 2003). It is for this reason that in the present project, specific attention is paid to this WIL design aspect. Scale questions focused upon whether alignment was a designed feature of the curriculum (Smith, 2008). Thus, two scales were developed to ascertain whether, either through the negotiated activities engaged in during the placement, or through the assessment tasks, students were required to:

- apply canonical knowledge to their work,

- reflect on their attempt to do this,

- reflect on the work they did or observed others doing in the workplace, and whether they were able to

- reflect on the canonical knowledge itself. 
Although very seldom an explicit recommendation in curriculum design theory, most curricula designs integrate the university student support silos - bureaucratic, administrative structures that exist to provide a range of social, psychological and learning supports to students (e.g. counselling, welfare, libraries, study advisory). Students in WIL placements are of course typically not at their host universities. They are however at workplaces, many of which have a range of their own appropriate support structures for their staff - counselling, debriefing, new employee inductions (relating to dissemination of functional workplace information and/or procedures), or even learning supports such as libraries. The recommendation is simply that curriculum designers deliberately make explicit use of these services in the delivery of the curriculum to their students.

The importance of supporting students during WIL programs is highlighted by Keogh et al., (2007), and others, studying students in engineering contexts (see for example Fleming, 2005; Freestone et al., 2007; Lynch, Goold, \& Blain, 2004; Newman, Daniels, \& Faulkner, 2003). There is then a clear need to measure and evaluate the integration of support services in WIL curricula, both at the student's university and within the workplace, which may help to alleviate the aforementioned stress and/or improve the learning process.

\section{Supervisor Access}

The notion of supervisor access relates to the contact maintained between the academic convenor (or appropriate others - e.g., tutors) and students in situ. The primary purpose of such contact is typically feedback on learning, support throughout the experience, educational supervision, and so on.

The importance of having access to academic or teaching support during a WIL course is outlined by Keogh et al., (2007). Other research by Lock and colleagues (Lock, Bullock, Hejmadi, \& Gould, 2009) revealed greater concerns, where only $14 \%$ of participants felt there was sufficient contact with academic staff. Thus, given the necessity (and perhaps paucity) of such teaching support, the current study sought to evaluate the contact maintained between the student and any academic convenors.

\section{Induction and Preparation Processes}

All university curricula require administration. Although achieving successful outcomes through WIL curricula depends largely on how academics / course convenors administer and manage pedagogical requirements, equal focus should also be placed on administrative tasks around preparing students (in both pedagogical and practical senses) for the work ahead, a process of which is acknowledged to be an extra burden on academics in charge of WIL curricula. These include establishing, maintaining and troubleshooting relationships with industry partners, keeping records, maintaining contact with students and workplace supervisors, addressing risks, OHS, ethical issues related to placements and many more.

Poorly administered curricula have consequences that may lead to the following:

- weakly integrated (or not integrated) disciplinary and practical learning (Ryan, Toohey, \& Hughes, 1996);

- $\quad$ unorganised experiences for students (Ryan et al., 1996);

- ill-prepared, and poorly motivated students (Abeysekera, 2006);

- ill-prepared academic and workplace supervisors (Ryan et al., 1996);

- ill-prepared workplaces (Pauling \& Komisarczuk, 2007); 
- uncooperative and indiscreetly utilitarian industry or community partners (Hughes, 1998; Ryan et al., 1996);

- stressful experiences of abandonment (Freestone et al., 2007).

Such trends point towards the need for better preparation of students so this study targeted the induction and preparation of students for the placement course, the systems for allocating students to industry partners (IPs), and course documentation.

\section{Method}

\section{Instrument item construction}

Given the six evaluation framework areas of interest, items were drafted to potentially measure each of these domains. The face validity of these items was then evaluated by a group of WIL practitioners and scholars who appraised the items for applicability, intelligibility and comprehensiveness of coverage.

An instrument was then prepared and piloted in which all items had 9-point response scales associated with them. This response format was chosen over a Likert style scale given findings by Lozano, Garcia-Cueto and Muniz (2008) who studied responses to 30 items by manipulating sample size (which ranged from $n=50$ to $n=500$ ) and response options (which ranged from two to nine). Lozano and colleagues found that as the response options increased, reliability and validity were enhanced and peaked at nine response points. In total 42 questions focused on the existence of various aspects of the curriculum's design; response extremes ranged from "not at all true" (of this curriculum) to "completely true".

\section{Sample}

The survey instrument was initially tested within a pilot study containing a small sample of students $(n=24)$ within one discipline of study. Students were recruited for the pilot and the main study by having WIL course convenors inviting students to complete the survey during class time. The survey was thus administered to groups of students enrolled in, and nearing completion of (or having just completed), various WIL placement streams within their programs of study.

Response rates ranged from 63\%-89\%, though more importantly for this study, the total number in the sample was adequate for the analyses being proposed, and the subsamples were representative.

The programs were chosen to ensure that they traversed a range of disciplinary contexts on the grounds that disciplinary cultures and teaching within those vary (Becher, 1989; Biglan, 1973a, 1973b; Shulman, 1986, 1987) in ways that might be relevant to this study.

The sample included Criminology $(\mathrm{n}=24)$, Engineering $(\mathrm{n}=102)$, and Film $(\mathrm{n}=14)$ in Australia, and Business $(n=79)$ in the United Kingdom. A total of 219 students completed the survey. Respondents had a mean age of 23.8 years $(\mathrm{SD}=0.29$; median=22; $\min =19 ; \max =42$ ). The discipline sub-samples did not differ significantly in terms of age. The sex distributions in each sub-sample are broadly representative of the enrolment distributions in those disciplines (e.g. engineering $81 \%$ male; criminology $75 \%$ female). Details of the sample groups and their corresponding WIL placements are described in Table 1. 
Table 1: Placement Stream Descriptions

\begin{tabular}{lll}
\hline Study Program & \multicolumn{1}{c}{ WIL Placement Description } & \multicolumn{1}{c}{ Duration } \\
\hline Engineering & $\begin{array}{l}\text { Final year and honours projects - industry setting with } \\
\text { industry partner supervision over specific tangible } \\
\text { projects involving real problems, innovative solutions } \\
\text { and prototype production. }\end{array}$ & Six months. \\
Intensive placement comprising 24 hour / all day activity \\
Film & $\begin{array}{l}\text { around the production process from script to film. } \\
\text { General degree involving a range of work placements } \\
\text { and work experience arrangements. }\end{array}$ & $\begin{array}{c}\text { Three weeks. } \\
\text { Business }\end{array}$ \\
$\begin{array}{lll}\text { Placements occurred across a variety of justice sector } \\
\text { Work settings (e.g., prisons). }\end{array}$ & $\begin{array}{l}\text { Predominantly 12 } \\
\text { weeks in length. }\end{array}$ \\
\hline
\end{tabular}

\section{Results and discussion}

\section{Confirmatory factor analysis (CFA)}

As an underlying factor structure was predicted prior to analysis, a Principal Axis Factoring (PAF) method of extraction was chosen rather than a Principal Components Analysis (PCA). As the factors were expected to be correlated, an oblique rotation (promax) was selected for the analysis (Tabachnick \& Fidell, 2000: 622).

\section{Factor analysis criteria}

During the scale purification process, a variety of factor analysis criteria were utilised, including: (a) Kaiser-Meyer-Olkin Measure of Sampling Adequacy (requirement of $\geq$ .6), (b) Bartlett's Test of Sphericity (requirement of $p<.05$ ), (c) item correlations to at least one other item by .3, (d) anti-image correlation matrix diagonals to be at least .5 or higher, (e) communalities to be at least .3 or higher, and (f) factor loadings to be at least .3 , with any cross-loadings to be less than .3. If particular items were found to have poor factor loadings, communalities, correlations or anti-diagonals, they were noted for possible exclusion. In accordance with these criteria, 13 items were removed.

\section{Factor Structure and validity of constructs}

Following the removal of problematic items, further PAF analysis of the WIL curricula items showed six factors to be interpretable, accounting for $76.7 \%$ of the variance.

Factor loadings for the items in the final analysis show strong construct validity with six independent and theoretically coherent factors, limited cross loadings and strong individual item loadings. Reliabilities of the factors were quite high with Cronbach's alpha ranging from 0.85 to 0.94 (see Table 3 for factor structure and reliabilities).

\section{Discriminant validity}

Scale scores were calculated for each individual in the dataset using Bartlett's method - which gives unbiased factor scores that correlate only with their own factors (Tabachnick \& Fidell, 2000:627). These correlations indicate further evidence for the independence of the six scales of the evaluation framework (see Table 2). 
Table 2: Inter-scale Pearson's r correlations (based on Bartlett's method)

\begin{tabular}{|c|c|c|c|c|c|c|}
\hline & 1 & 2 & 3 & 4 & 5 & 6 \\
\hline 1. Authenticity & 1 & & & & & \\
\hline 2. Sup. Access & $.17^{*}$ & 1 & & & & \\
\hline 3. IPP & $.33^{\star *}$ & $.29^{\star *}$ & 1 & & & \\
\hline 4. ALIGN_Assts & $.49^{\star \star}$ & $.36^{\star \star}$ & $.40^{\star *}$ & 1 & & \\
\hline 5. ALIGN_TLAs & $.61^{\star *}$ & $.23^{\star \star}$ & $.51^{\star \star}$ & $.60^{\star *}$ & 1 & \\
\hline 6. ILS & $.28^{* *}$ & $.29 * *$ & $.51^{\star \star}$ & $.42^{\star *}$ & $.48^{* *}$ & 1 \\
\hline
\end{tabular}

Low correlations between theoretically independent constructs is an indication of divergent or discriminate validity; high correlations between related constructs a are an indication of convergent validity (Campbell \& Fiske, 1959). Excluding two relatively high inter-scale correlations $(0.60$ and 0.61$)$ the correlations range from 0.17 to 0.51 . The relatively higher correlation $(r=.60)$ between the alignment variables (TLAs and assessment) is expected since course coordinators who ensure alignment of the assessments and the learning objectives will be more likely than others to also ensure the alignment of the activities and the learning objectives.

Similarly, the correlation ( $\mathrm{r}=.61)$ between the authenticity of the workplace experience and the teaching and learning activities is not unexpected given their mutual focus on meaningful activity in the work placement. Neither of these correlations is sufficiently high to warrant concerns of redundancy or co-linearity, however. Furthermore these last two constructs are theoretically distinct because the focus of the activities scale is on the reflective integrative learning, whereas the focus of the authenticity scale is purely upon the notions of the meaningfulness and consequentiality of the work done during the placement. 


\begin{tabular}{|c|c|c|c|c|c|c|c|c|}
\hline & & & Authenticity & $\begin{array}{l}\text { Alignment } \\
\text { TLAs }\end{array}$ & $\begin{array}{c}\text { Alignment } \\
\text { Assessments }\end{array}$ & $\begin{array}{l}\text { Integrated Learning } \\
\text { Support (ILS) }\end{array}$ & $\begin{array}{l}\text { Supervisor } \\
\text { Access }\end{array}$ & $\begin{array}{c}\text { Induction \& } \\
\text { Preparation } \\
\text { Processes }\end{array}$ \\
\hline & & & $\begin{array}{c}1 \\
\alpha=.90\end{array}$ & $\begin{array}{c}2 \\
\alpha=.94\end{array}$ & $\begin{array}{c}3 \\
\alpha=.94\end{array}$ & $\begin{array}{c}4 \\
\alpha=.85\end{array}$ & $\begin{array}{c}5 \\
\alpha=.86\end{array}$ & $\begin{array}{c}6 \\
\alpha=.90\end{array}$ \\
\hline AUTH & & meaningful work, tasks and activities & 0.73 & & & & & \\
\hline AUTH & $\mathrm{X}$ & worked with autonomy or responsibility & 0.72 & & & & & \\
\hline AUTH & & workplace gave opportunities that were relevant & 0.73 & & & & & \\
\hline AUTH & & work was important or consequential & 0.86 & & & & & \\
\hline AUTH & & work relevant to organisation's goals or outcomes & 0.93 & & & & & \\
\hline AUTH & $\mathrm{X}$ & work resulted in worthwhile outcome for the organisation & 0.73 & & & & & \\
\hline ALGN & A1 & apply the theories I had learned in class to the work & & 0.73 & & & & \\
\hline ALGN & A2 & critically appraise the theories in relation to the work & & 0.81 & & & & \\
\hline ALGN & A3 & critically appraise practice in the workplace & & 0.65 & & & & \\
\hline ALGN & A4 & apply or develop professional skills in the workplace & & 0.78 & & & & \\
\hline ALGN & A5 & reflect on application of disc. knowledge/theory to work & & 0.79 & & & & \\
\hline ALGN & ST1 & effective ways of assessing whether achieved goals & 0.32 & & 0.49 & & & \\
\hline ALGN & ST2 & asst's focused on application of theory in workplace & & & 0.83 & & & \\
\hline ALGN & ST3 & ass'd critical appraisal of the applicability of theory & & & 0.99 & & & \\
\hline ALGN & ST4 & critical appraisal of practice engaged in workplace & & & 0.77 & & & \\
\hline ALGN & ST5 & ass'd developm't of prof. skills learned in workplace & & & 0.65 & & & \\
\hline ILS1 & & I was encouraged to use workplace support services & & & & 0.80 & & \\
\hline ILS2 & & workplace support services integral & & & & 0.94 & & \\
\hline ILS3 & & university support services integral to course & & & & 0.70 & & \\
\hline SUP.I & ESS1 & It was easy for me to contact my academic supervisor & & & & & 0.88 & \\
\hline SUP.I & ESS2 & My academic supervisor got back to me quickly & & & & & 0.92 & \\
\hline SUP.I & ESS3 & interactions with my academic supervisor were useful & & & & & 0.70 & \\
\hline IPP1 & $\mathrm{X}$ & system simple for connecting students \& workplaces & & & & & & 0.91 \\
\hline IPP2 & $\mathrm{x}$ & allocation system ensured a good fit & & & & & & 0.98 \\
\hline IPP3 & & support materials cover every possible problem & & & & & & 0.64 \\
\hline IPP4 & & easy to get assistance for problems in workplace & & & & & & 0.48 \\
\hline IPP5 & & roles and responsibilities clearly documented & & & & & & 0.79 \\
\hline IPP6 & & documentation dealt with issues of concern to me & & & & & & 0.69 \\
\hline IPP7 & $\mathrm{X}$ & clear to me what to do in the event of a problem & & & & & & 0.69 \\
\hline
\end{tabular}

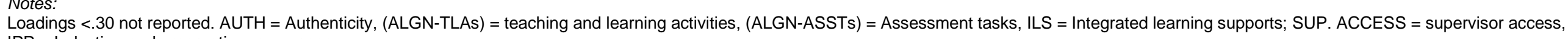
IPP = Induction and preparation processe

' $X$ ' indicates an indicator variable trimmed from the model during the SEM analysis on the basis of theory and low (<.50) SMC. 


\section{Structural equation modelling (SEM)}

To compare alternative models, a confirmatory factor analysis (CFA) was also conducted using SEM. This is achieved by calculating measures of fit between the proposed models and the data. A model that fits the data well is determined by several criteria:

- A comparative fit index (CFI) of greater than 0.9 (Kline, 1998);

- A non-normed fit index (NNFI/TLI) of 0.95 or greater (L. Hu \& Bentler, 1999); and

- A root mean square error of approximation (RMSEA) of less than 0.08 (Kline, 1998).

The first model tested was a single-factor model in which one latent construct predicts all observed variables and explains all the observed correlations. This model had very poor fit to the data $(\mathrm{CFI}=0.537$; TLI/NNFI $=0.466$; RMSEA $=0.162)$. In the second test, the evaluation framework as a six-factor model was analysed. In this case the fit was markedly better $(\mathrm{CFI}=0.895 ; \mathrm{TLI} / \mathrm{NNFI}=0.874$; RMSEA $=0.079)$. For this model the estimates of the squared multiple correlations (SMCs) for each observed variable in the model ranged from 0.47 to 0.90 . The SMCs are an estimate of the amount of variance in each observed variable that is explained by the latent construct. This model was then trimmed by removing items with SMCs less than 0.5. The deleted items are marked with an ' $\mathrm{X}$ ' in Table 2. One item was not deleted in spite of an SMC of 0.53 because it was one of only three indicators of one of the latent constructs. One further deletion was made of an item with an SMC of 0.6 because it was conceptually very similar to one deleted initially. The resulting model, with 5 items deleted, had a better fit to the data (RMSEA $=0.071 ; \mathrm{CFI}=0.931 ; \mathrm{TLI} / \mathrm{NNFI}=0.912$ ). This basic 6 -factor (trimmed) model then had the best fit to the data and confirmed the factor analyses previously conducted.

\section{Utility for evaluation across different disciplines}

Evidence for the utility of these measures resides in the degree to which they discriminate between disciplines. Different disciplines are known to be associated with different scholarly and pedagogical traditions (Becher, 1989; Biglan, 1973a, 1973b; Shulman, $1986,1987)$. Thus, it is a reasonable expectation that because different disciplines also vary on the ways in which they implement WIL (Patrick et al., 2008) they will obtain different scores on a series of measures of aspects of WIL curricula. This is evidenced in Figure 1 displaying the means on each of the six factors by disciplines. The identity of the disciplines is disguised by the use of letters (A,B,C,D) since specific discipline differences are not the focus of the study. 


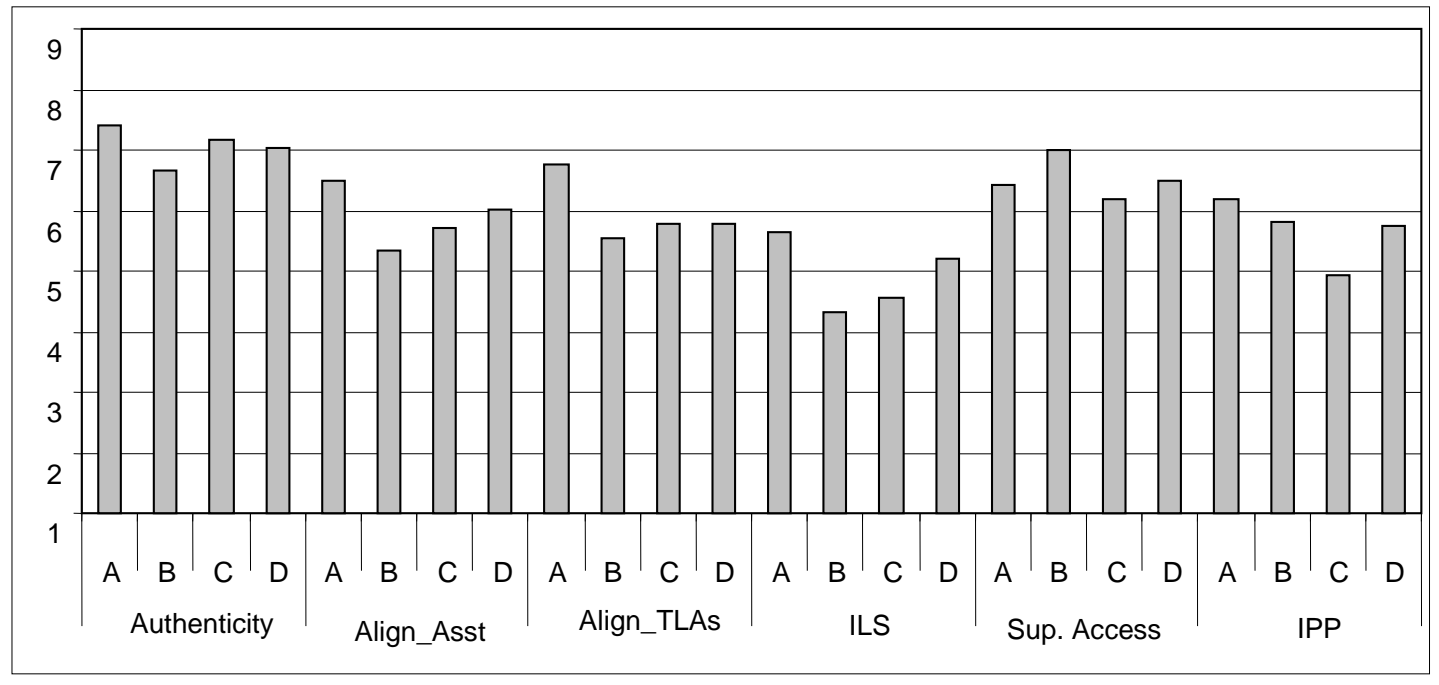

Figure 1: Mean scores on main factors by discipline group

\section{Summary and Conclusions}

Work-integrated learning curricula are an increasingly common feature of the HE landscape in Australia and elsewhere (Abeysekera, 2006; Costley \& Armsby, 2007; Crespo \& Dridi, 2007; Foskett, 2005; Orrell, 2004; Rhodes \& Shiel, 2007), and have a long-standing traditional place in professional education (Orrell, 2004; Ryan et al., 1996). There is considerable investment in expanding WIL in the HE sector, beyond those programs in which it has traditionally featured (Abeysekera, 2006; Edmond, 2007; Holt, Mackay, \& Smith, 2004; Orrell, 2004; Ryan et al., 1996). Further, WIL is a relatively expensive curriculum compared with standard lecture-plus-tutorial designs. For these reasons it is imperative that adequate measurement models for conceiving and measuring the essential aspects of WIL curricula be devised; this is the imperative that motivates the present study. The generalisability of the measurement framework to other institutions that deploy WIL is expected to be unproblematic by extension, since a range of disciplines was used in the present study, and two institutions; however this will be tested in future work.

Although there have been previous attempts to develop a quantitative evaluation instruments, no one framework adequately captures essential WIL curricula elements. Instruments such as the WEQ are lacking in this regard due to their failure to capture pedagogically-relevant characteristics of WIL curricula, especially the authenticity of the workplace experience and the incorporation of integrative learning as a learning outcome.

The idea that integrative learning should form a central part of the identifiable character of a WIL curriculum makes perfect sense, but when operationalising this construct it turns out, not altogether unexpectedly, that this is achieved through focusing on the alignment of TLAs and assessments with integrative learning outcomes. As already argued, these integrative learning outcomes are (or perhaps ought to be) the key objectives of WIL curricula.

Thus the evaluation framework appraised in this study, and confirmed as an empirical model with six constructs, provides a useful framework for understanding and focusing 
evaluation of the key aspects of WIL curricula, and may be useful for future research. The proposed curricula evaluation framework underpins a valid measuring instrument. This instrument may serve to focus attention on these particular aspects during course design and evaluation. Given the variability in the types of WIL courses in existence, some of these curricula components may be of less importance in some designs than in others. As such, this instrument is not intended to serve as a prescription for all WIL curriculum designs, but rather as means for evaluating WIL curricula.

One specific weakness in the measurement model reported here is that the measurement of the interactions between students and their academic supervisors was limited to the availability or accessibility of supervisors and the utility of their advice. This is an area that should be measured in more detail than this, and is another area for future research as is the exploration of relationships between aspects of the curriculum "process" and the resulting "products" (i.e., student learning outcomes and satisfaction) which will help to fill identified research gaps (X. Hu et al., 2009) and provide insight as to what WIL course components contribute to the development of student generic capabilities. 


\section{References}

Abeysekera, I. (2006). Issues Relating to Designing a Work-integrated Learning Program in an Undergraduate Accounting Degree Program and its Implications for the Curriculum. Asia-Pacific Journal of Cooperative Education, 7(1), 7-15.

Alderman, B., \& Milne, P. (2005). A Model for Work-Based Learning. Maryland: The Scarecrow Press, Inc.

Ballantine, J., \& McCourt Larres, P. (2007). Cooperative learning: a pedagogy to improve students' generic skills? Education and Training, 49(2), 126-137.

Barnett, R., Parry, G., \& Coate, K. (2001). Conceptualising Curriculum Change. Teaching in Higher Education, 6(4), 435 - 449.

Bath, D., Smith, C., Stein, S., \& Swann, R. (2004). Beyond mapping and embedding graduate attributes: bringing together quality assurance and action learning to create a validated and living curriculum. Higher Education Research \& Development, 23(3), 313-328.

Becher, T. (1989). Academic Tribes and Territories: Intellectual enquiry and the cultures of disciplines. Milton Keynes: Open University Press.

Biggs, J. (1996). Enhancing teaching through constructive alignment. Higher Education, 32(3), 347-364.

Biglan, A. (1973a). The characteristics of subject matter in different academic areas. Journal of Applied Psychology, 57(3), 195-203.

Biglan, A. (1973b). Relationships between subject matter characteristics and the structure and output of university departments. Journal of Applied Psychology, 57(3), 204213.

Billett, S. (2001). Learning in the workplace: Strategies for effective practice. Crow's Nest: Allen and Unwin.

Boud, D., Keogh, R., \& Walker, D. (Eds.). (1985). Reflection: Turning experience into learning. London: Kogan Page.

Boud, D., \& Solomon, N. (Eds.). (2001). Work-based learning : a new higher education? Buckinghamshire: Society for Research into Higher Education \& Open University Press.

Boud, D., \& Walker, D. (1991). Experience and learning: reflection at work. Melbourne: Deakin University Press.

Campbell, D.T., \& Fiske, D.W. (1959). Convergent and discriminant validation by the multitrait-multimethod matrix. Psychological Bulletin, 56(2), 81-105.

Costley, C., \& Armsby, P. (2007). Work-based learning assessed as a field or a mode of study. Assessment \& Evaluation in Higher Education, 32(1), 21-33.

Crebert, G., Bates, M., Bell, B., Patrick, C., \& Cragnolini, V. (2004). Ivory Tower to Concrete Jungle Revisited. Journal of Education and Work, 17(1), 47-70.

Crespo, M., \& Dridi, H. E. (2007). Intensification of university-industry relationships and its impact on academic research. Higher Education, 54(1), 61-84. 
Dewey, J. (1939). Democracy and Education. New York: Free Press / MacMillan.

Duignan, J. (2003). Placement and adding value to the academic performance of undergraduates: reconfiguring the architecture - an empirical investigation. Journal of Vocational Education \& Training, 55(3), 335 - 350.

Dymock, D., \& Gerber , R. (2002). Unintegrated training? Exploring links between offand on-the-job learning. Education + Training, 44(1), 23-30.

Eakins, P. (2000). The importance of context in work placements. Journal of Cooperative Education, 35(2/3), 61-67.

Eames, C. (2003). Learning to Work: Becoming a Research Scientist Through Work Experience Placements. Asia-Pacific Journal of Cooperative Education, 4(2), 715.

Edmond, N. (2007). Between a rock and a hard place The role of HE and foundation degrees in workforce development. Education + Training, 49(3), 170-181.

Fleming, S.T. (2005). Talking past each other: Student and staff reflection in undergraduate software projects. Issues in Informing Science and Information Technology, 2, 93-102.

Foskett, R. (2005). Collaborative Partnership in the Higher Education Curriculum: a cross-sector study of foundation degree development. Research in PostCompulsory Education, 10(3), 351-372.

Freestone, R., Williams, P., Thompson, S., \& Trembath, K. (2007). A quantitative approach to assessment of work-based learning outcomes: an urban planning application. Higher Education Research \& Development, 26(4), 347-361.

Harvey, L. (2005). Embedding and Integrating Employability. In R. A. Voorhees and L. Harvey (Eds.), Workforce Development and Higher Education: A Strategic Role for Institutional Research (pp. 13-28). San Francisco: Jossey-Bass.

Herrington, A., \& Herrington, J. (2006). Authentic learning environments in higher education. Hershey, PA: Information Science Publishing.

Holt, D., Mackay, D., \& Smith, R. (2004). Developing Professional Expertise in the Knowledge Economy: Integrating Industry-Based Learning with the Academic Curriculum in the Field of Information Technology Asia-Pacific Journal of Cooperative Education, 5(2), 1-11.

Hu, L., \& Bentler, P.M. (1999). Cutoff criteria for fit indices in covariance structure analysis: Conventional criteria verses new alternatives. Structural Equation Modelling, 6(1), 1-55.

Hu, X., Abadeer, O., \& Husman, C. (2009). Evaluation of Engineering Work Experience Programs (I): Principles. 20th Australasian Association for Engineering Education Conference (available online at:http://aaee.com.au/conferences/AAEE2009/PDF/AUTHOR/AE090059.PDF), 919-923.

Hughes, C. (1998). Practicum Learning: perils of the authentic workplace. Higher Education Research \& Development, 17(2), 207 - 227. 
Keating, S. (2006). Learning in the workplace: A literature review: Postcompulsory Education Centre, University of Victoria.

Kember, D., Leung, D.Y.P., Jones, A., Loke, A.Y., Mckay, J., Sinclair, K., et al. (2000). Development of a Questionnaire to Measure the Level of Reflective Thinking. Assessment \& Evaluation in Higher Education, 25(4), 381-395.

Keogh, K., Sterling, L., \& Venables, A. (2007). A scalable and portable structure for conducting successful year-long undergraduate software team projects. Journal of information technology education, 6, 516-540.

Kline, R. (1998). Principles and practice of structural equation modelling. New York: Guildford Press.

Lave, J., \& Wenger, E. (1991). Situated learning. Legitimate peripheral participation. Cambridge: Cambridge University Press.

Lock, G., Bullock, K., Hejmadi, M., \& Gould, V. (2009). Engineering education. Journal of the Higher Education Academy, 4(1), 1-13.

Lozano, L.M., García-Cueto, E., \& Muñiz, J. (2008). Effect of the Number of Response Categories on the Reliability and Validity of Rating Scales. Methodology, 4(2), 73-79.

Lynch, K., Goold, A., \& Blain, J. (2004). Students' pedagogical preferences in the delivery of IT capstone courses. Issues in Informing Science and Information Technology, 1, 431-442.

Martin, E. (1997). The effectiveness of different models of work-based university education. Canberra: Department of Employment, Education, Training and youth Affairs (Evaluation and Investigations Program).

McInnes, C., \& James, R. (2003). New Scales. Paper presented at the Graduate: Outcomes Quality and the Future - GCCA Symposium, 24-25 March, Canberra, Australia.

McInnis, C., Griffin, P., James, R., \& Coates, H. (2001). Development of the Course Experience Questionnaire (CEQ) (No. 6662HERC01A). Melbourne: Centre for the Study of Higher Education (CSHE) and Department of Education Training and Youth Affairs (DETYA).

Moore, D.T. (2004). Curriculum at work: An educational perspective on the workplace as a learning environment. The Journal of Workplace Learning, 16(6), 325-340.

Newman, I., Daniels, M., \& Faulkner, X. (2003). Open ended group projects: A 'tool' for more effective Teaching. ACE '03 Proceedings of the fifth Australasian conference on Computing education - Volume 20, 95-103.

Orrell, J. (2004, July). Work-integrated learning programmes: Management and educational quality. Paper presented at the Australian Universities Quality Forum, Adelaide.

Patrick, C., Peach, D., Pocknee, C., Webb, F., Fletcher, M., \& Pretto, G. (2008). The WIL (Work Integrated Learning) report: A national scoping study - Australian Learning and Teaching Council [ALTC] Final report. Brisbane: Queensland University of Technology. 
Pauling, J.W., \& Komisarczuk, P. (2007). A review of work experience in a bachelor of information technology. Paper presented at the In proceedings of the Australasian Computer Education (ACE) Conference, January, 2007, Australasian Computer Science Week (ACSW) 2007, Ballarat, NSW, Australia.

Precision Consultancy, \& Commonwealth of Australia. (2007). Graduate employability skills. Canberra: Commonwealth of Australia.

Radcliffe, D., \& Brown, A. (2003). Fostering professional development through integrating work and formal learning. Paper presented at the 33rd ASEEI IEEE Frontiers in Education Conference, 5-8 November, 2003, Boulder, Colorado.

Ramsden, P. (1991). A performance indicator of teaching quality in higher education: The Course Experience Questionnaire. Studies in Higher Education, 16(2), 129150.

Rhodes, G., \& Shiel, G. (2007). Meeting the needs of the workplace and the learner through work-based learning Garth and Gillian Journal of Workplace Learning, 19(3), 173-187.

Ryan, G., Toohey, S., \& Hughes, C. (1996). The purpose, value and structure of the practicum in higher education: A literature review. Higher Education, 31(3), 355377.

Shulman, L.S. (1986). Those who understand: Knowledge growth in teaching. Educational Researcher, 15(2), 4-14.

Shulman, L.S. (1987). Knowledge and teaching: Foundations of the new reform. Harvard Educational Review, 57(1), 1-22.

Smith, C. D. (2008). Design-focused evaluation. Assessment \& Evaluation in Higher Education, 33(6), 631-645.

Smith, C.D., \& Bath, D.M. (2006). The role of the learning community in the development of discipline knowledge and generic graduate outcomes. Higher Education, 51(2), 259-286.

Stein, S., Andrews, T., \& Isaacs, G. (2001). Incorporating authentic learning Experiences within a business management course, Australian Association for Research in Education. The University of Notre Dame Fremantle Australia: University of Queensland.

Tabachnick, B.G., \& Fidell, L.S. (2000). Using multivariate statistics (4th ed.). London: Allyn and Bacon.

Thacker, R. (2002). Revising the HR curriculum: An academic/ practitioner partnership. Education + Training, 44(1), 31-39.

Universities Australia. (2008). Universities Australia Position Paper 3/08: A National internship Scheme: Enhancing the skills and work-readiness of Australian university graduates. Canberra: Universities Australia.

University of Western Australia. (1999). Work-based learning Issues of Teaching and Learning, 5(7).

Wright, P. (Ed.). (1990). Industry and Higher Education Collaboration to improve students' learning and training. Buckingham: Open University Press. 
Yorke, M. (2006). Employability in higher education: what it is - what it is not. York: The Higher Education Academy. 